\title{
Underweight status predicts a poor prognosis in elderly patients with colorectal cancer
}

\author{
MANABU KANEKO, SHIN SASAKI, KOSUKE OZAKI, KAZUHIRO ISHIMARU, \\ EMI TERAI, HIROSHI NAKAYAMA and TOSHIYUKI WATANABE \\ Department of Surgery, Omori Red Cross Hospital, Tokyo 143-8527, Japan
}

Received March 23, 2016; Accepted July 1, 2016

DOI: $10.3892 / \operatorname{mco} .2016 .964$

\begin{abstract}
The aim of the present study was to evaluate the effect of underweight status on the survival of elderly patients undergoing surgery for colorectal cancer (CRC). A total of 113 patients aged $\geq 75$ years who underwent curative surgery for CRC were included. In addition to standard perioperative variables, body mass index (BMI) was assessed. The patients were categorized as underweight $\left(\mathrm{BMI}<18.5 \mathrm{~kg} / \mathrm{m}^{2}\right)$ or non-underweight $\left(\mathrm{BMI} \geq 18.5 \mathrm{~kg} / \mathrm{m}^{2}\right)$. The 3 -year overall survival (OS) and cancer-specific survival (CSS) were analyzed. Of the 113 patients, 24 (21\%) were underweight. The two groups were well-balanced regarding all factors evaluated. In the multivariate analysis, underweight status was an independent indicator of lower 3-year OS [hazard ratio $(\mathrm{HR})=2.65$; 95\% confidence interval $(\mathrm{CI}): 1.08-6.50 ; \mathrm{P}=0.033]$ and CSS $(\mathrm{HR}=3.51,95 \% \mathrm{CI}: 1.16-10.60 ; \mathrm{P}=0.025)$ rates. Compared with the non-underweight group, the underweight group had significantly worse 3 -year OS (66.7 vs. $86.5 \%$, respectively; $\mathrm{P}=0.017$ ) and CSS (74.1 vs. 90.9\%, respectively; $\mathrm{P}=0.025$ ) rates. Therefore, underweight status was a significant risk factor for poor survival in elderly CRC patients. The development of effective nutritional interventions may improve the prognosis of such patients.
\end{abstract}

\section{Introduction}

Colorectal cancer (CRC) is the third and second most commonly diagnosed cancer in men and women, respectively, with an estimated 1.4 million new cases and nearly 700,000 deaths in 2012 worldwide (1). Approximately 60\% of CRC patients are aged $>70$ years (2). The number of elderly individuals is increasing worldwide due to the increase in the average life span. As a result, the number of middle-old (75-84 years)

Correspondence to: Dr Manabu Kaneko, Department of Surgery, Omori Red Cross Hospital, 4-30-1 Chuo, Ota-ku, Tokyo 143-8527, Japan

E-mail: m.kaneko@fancy.ocn.ne.jp

Key words: underweight, body mass index, nutritional status, colorectal cancer, prognosis and oldest-old patients (>85 years) diagnosed with CRC is expected to increase. Although potentially curative resection is not possible in approximately one-fourth of the patients (3), surgery is the most reliable treatment modality. In the preoperative management of elderly patients, cardiovascular risk, respiratory function and the presence of comorbidities are thoroughly assessed. However, nutritional status assessment may be overlooked in routine preoperative evaluation, despite the fact that undernutrition is associated with an increased risk of poor tissue healing and impaired immune function (4), and previous studies reporting that poor nutritional status was associated with worse survival of elderly patients who underwent surgery for lung, ovarian and primary peritoneal cancer $(4,5)$.

Body mass index (BMI) is a useful tool in clinical practice for assessing adult nutritional status, and individuals are considered to be underweight if their BMI is $<18.5 \mathrm{~kg} / \mathrm{m}^{2}$. A BMI $<18.5 \mathrm{~kg} / \mathrm{m}^{2}$ also indicates undernutrition (6). Several studies conducted among subjects of a broad age range reported that underweight status was a significant predictor of poorer overall survival in CRC (7-13). However, to the best of our knowledge, no study has yet been conducted to investigate the association between underweight status and survival outcome in elderly CRC patients.

The aim of this study was to investigate whether underweight status was associated with a worse survival outcome in elderly patients undergoing curative surgery for CRC.

\section{Materials and methods}

Patient population. A total of 113 Japanese patients with pathologically confirmed stage I-III CRC, aged $\geq 75$ years, who underwent curative surgery between January, 2004 and June, 2012 at the Department of Surgery, Omori Red Cross Hospital (Tokyo, Japan) were retrospectively analyzed. The patients were followed up for $\geq 3$ years or until death. Patients with cancer of other organs were excluded. The medical charts of the 113 patients were retrieved from our registry, and clinical, pathological and survival data were collected. The factors included in this study were age, gender, Charlson Comorbidity Index (14), the calculation of which did not include cancer diagnoses, American Society of Anesthesiologists physical status, tumor site, disease stage according to the Union for International Cancer Control (15), histology and BMI at the 
time of diagnosis. BMI was calculated as weight in kilograms divided by the square of the height in meters $\left(\mathrm{kg} / \mathrm{m}^{2}\right)$. Patients were divided into underweight $\left(\mathrm{BMI}<18.5 \mathrm{~kg} / \mathrm{m}^{2}\right)$ and non-underweight (BMI $\geq 18.5 \mathrm{~kg} / \mathrm{m}^{2}$ ) groups, according to the World Health Organization (WHO) classification (6). The associations between 3-year overall survival (OS) or cancer-specific survival (CSS) and the patients' clinicopathological data were analyzed. The 3-year OS, CSS and recurrence-free survival (RFS) curves were then estimated for each group using the Kaplan-Meier method. The review board of the hospital approved the study protocol.

Statistical analysis. The associations between BMI and the clinicopathological parameters were assessed using the Pearson's Chi-square or Fisher's exact tests, as appropriate. Cox regression analyses were performed to analyze the survival outcome in univariate and multivariate analyses. Variables that were significant in the univariate analysis were examined in the multivariate analysis. OS, CSS and RFS were determined from the date of surgery to the date of death from any cause, cancer-specific death and recurrence, respectively. The Kaplan-Meier survival curves were compared using the log-rank test. All reported P-values were two-tailed and those $<0.05$ were considered to indicate statistically significant differences. All data were analyzed using EZR version 1.24 software for Windows (Saitama Medical Center, Jichi Medical University, Saitama, Japan), which is a graphical user interface for R (The R Foundation for Statistical Computing, Vienna, Austria) (16).

\section{Results}

Patient characteristics. Of the 113 patients, 20 (17.6\%) died within 3 years of surgery: 14 patients succumbed to $\mathrm{CRC}$, whereas the remaining 6 patients died from other causes. The median BMI was $21.3 \mathrm{~kg} / \mathrm{m}^{2}$ (range, $12.6-30.2 \mathrm{~kg} / \mathrm{m}^{2}$ ), and 1 patient $(0.8 \%)$ had a BMI of $\geq 30 \mathrm{~kg} / \mathrm{m}^{2}$. A total of 24 patients $(21 \%)$ were in the underweight and $89(79 \%)$ in the non-underweight group.

The clinical and pathological characteristics of the patients, stratified by BMI, are listed in Table I. The two groups were well-balanced regarding all factors evaluated, although underweight patients exhibited a trend toward a higher Charlson Comorbidity Index score compared with patients who were not underweight $(\mathrm{P}=0.060)$.

Analysis of $O S$ and CSS. The results of the univariate and multivariate Cox regression analyses for 3-year OS are shown in Table II. In the univariate analysis, the factors significantly associated with poorer 3 -year OS were advanced disease stage $(\mathrm{P}=0.001)$ and underweight status $(\mathrm{P}=0.023)$. The multivariate Cox regression analysis demonstrated that advanced disease stage [hazard ratio $(\mathrm{HR})=4.31 ; 95 \%$ confidence interval (CI): 1.76-10.58; $\mathrm{P}=0.001]$ and underweight status $(\mathrm{HR}=2.65$; 95\% CI: $1.08-6.50 ; \mathrm{P}=0.033$ ) were independently associated with worse 3 -year OS.

The results of the univariate and multivariate Cox regression analyses for 3-year CSS are shown in Table III. The factors significantly associated with a poorer 3-year CSS were advanced disease stage $(\mathrm{P}<0.001)$, undifferentiated histology
$(\mathrm{P}=0.016)$ and underweight status $(\mathrm{P}=0.034)$. The multivariate Cox regression analysis revealed that advanced disease stage (HR=6.69; 95\% CI: 2.08-21.44; $\mathrm{P}=0.001)$, undifferentiated histology $(\mathrm{HR}=4.37 ; 95 \% \mathrm{CI}: 1.15-16.62 ; \mathrm{P}=0.030)$, and underweight status $(\mathrm{HR}=3.51 ; 95 \% \mathrm{CI}$ : $1.16-10.60 ; \mathrm{P}=0.025)$ were independently associated with a worse 3 -year CSS.

Patients in the underweight group had a significantly worse 3 -year OS rate compared with those in the non-underweight group (66.7 vs. $86.5 \%$, respectively; $\mathrm{P}=0.017)$ and CSS rate (74.1 vs. $90.9 \%$, respectively; $\mathrm{P}=0.025$ ) (Fig. 1). There was no significant difference in the 3 -year RFS rate between the underweight and non-underweight groups (74.3 vs. $77.1 \%$; $\mathrm{P}=0.74)$.

\section{Discussion}

The association between underweight status and the prognosis of CRC patients has been reported in several studies conducted among patients of all ages, and underweight patients have been shown to have a worse OS (7-13). However, Hines et al reported that underweight patients were on average older compared with those in other BMI categories, and more frequently had moderate or severe comorbidities compared with their younger counterparts (10); thus, older age and comorbidities were possible confounding factors when attempting to determine the association between BMI categories and survival outcome in CRC patients (10). In this study, among elderly CRC patients, we found that underweight status, but not the Charlson Comorbidities Index score, was an independent risk factor for all-cause and cancer-specific mortality. Therefore, the worse prognosis of underweight patients was not solely attributed to their older age and more severe comorbidities.

It remains unclear whether underweight status exerts a significant negative effect on CSS or RFS in patients with CRC (7-13). Doria et al reported an increased risk of cancer-related death among underweight patients with colon cancer. Two other studies reported that underweight status per se was not a significant risk factor for CSS in CRC, and that underweight patients tended to succumb to non-cancer events, which was attributed, at least in part, to an underlying comorbid illness $(8,12)$. In regards to RFS, it has previously been reported that underweight patients have a higher risk of cancer recurrence $(12,13)$. Conversely, other investigators found no association between underweight status and RFS $(7,11)$. In the present study, we observed that underweight patients had a worse CSS but similar RFS with non-underweight patients. One possible explanation for these findings is that underweight status may be associated with more severe comorbidities and a poor performance status, thus preventing effective chemotherapeutic treatment or surgery when the disease recurs (17). Indeed, underweight patients in this study exhibited a trend toward a higher Charlson Comorbidity Index score and were less likely to receive salvage treatment for recurrent disease compared with patients who were not underweight (16 vs. 75\%, respectively; data not shown).

Underweight status in elderly patients may be associated with the loss of muscle and fat mass due to sarcopenia and/or cachexia. Sarcopenia in elderly individuals was defined as the "progressive loss of muscle mass and strength with a risk 
Table I. Baseline characteristics of the CRC patients stratified by BMI.

\begin{tabular}{|c|c|c|c|}
\hline & Non-underweight ${ }^{\mathrm{a}}$ & Underweight $^{\mathrm{b}}$ & \\
\hline Characteristics & $\mathrm{n}(\%)$ & $\mathrm{n}(\%)$ & P-value \\
\hline Age (years) & & & 0.25 \\
\hline$<85$ & $73(82.0)$ & $17(70.8)$ & \\
\hline$\geq 85$ & $16(18.0)$ & $7(29.2)$ & \\
\hline Gender & & & 0.25 \\
\hline Female & $47(52.8)$ & $16(66.7)$ & \\
\hline Male & $42(47.2)$ & $8(33.3)$ & \\
\hline Charlson comorbidity index & & & 0.060 \\
\hline 0,1 & $78(87.6)$ & $17(70.8)$ & \\
\hline$\geq 2$ & $11(12.4)$ & $7(29.2)$ & \\
\hline ASA physical status & & & 0.19 \\
\hline I, II & $63(70.8)$ & $13(54.2)$ & \\
\hline III, IV & $26(29.2)$ & $11(45.8)$ & \\
\hline Tumor site & & & 0.10 \\
\hline Colon & $69(77.5)$ & $14(58.3)$ & \\
\hline Rectum & $20(22.5)$ & $10(41.7)$ & \\
\hline Stage & & & 0.45 \\
\hline I, II & $66(74.2)$ & $16(66.7)$ & \\
\hline III & $23(25.8)$ & $8(33.3)$ & \\
\hline Histology & & & 0.67 \\
\hline Differentiated & $83(93.3)$ & $22(91.7)$ & \\
\hline Undifferentiated & $6(6.7)$ & $2(8.3)$ & \\
\hline
\end{tabular}

${ }^{\mathrm{a}} \mathrm{BMI} \geq 18.5 \mathrm{~kg} / \mathrm{m}^{2} .{ }^{\mathrm{b}} \mathrm{BMI}<18.5 \mathrm{~kg} / \mathrm{m}^{2}$. CRC, colorectal cancer; BMI, body mass index; ASA, American society of anesthesiologists.

Table II. Cox regression analyses of 3-year overall survival.

\begin{tabular}{|c|c|c|c|c|c|c|}
\hline \multirow[b]{2}{*}{ Variables } & \multicolumn{3}{|c|}{ Univariate analysis } & \multicolumn{3}{|c|}{ Multivariate analysis } \\
\hline & HR & $95 \% \mathrm{CI}$ & P-value & HR & $95 \% \mathrm{CI}$ & P-value \\
\hline \multicolumn{7}{|l|}{ Age, years } \\
\hline$\geq 85$ vs. $<85$ & 1.76 & $0.67-4.58$ & 0.24 & & & \\
\hline \multicolumn{7}{|l|}{ Gender } \\
\hline Male vs. female & 1.60 & $0.66-3.86$ & 0.29 & & & \\
\hline \multicolumn{7}{|l|}{ Charlson comorbidity index } \\
\hline$\geq 2$ vs. 0,1 & 1.36 & $0.45-4.07$ & 0.57 & & & \\
\hline \multicolumn{7}{|l|}{ ASA physical status } \\
\hline III, IV vs. I, II & 1.72 & $0.71-4.16$ & 0.22 & & & \\
\hline \multicolumn{7}{|l|}{ Tumor site } \\
\hline Rectum vs. colon & 0.86 & $0.31-2.39$ & 0.78 & & & \\
\hline \multicolumn{7}{|l|}{ Stage } \\
\hline III vs. I, II & 4.47 & $1.82-10.95$ & 0.001 & 4.31 & $1.76-10.58$ & 0.001 \\
\hline \multicolumn{7}{|l|}{ Histology } \\
\hline Undifferentiated vs. differentiated & 3.16 & $0.92-10.80$ & 0.066 & & & \\
\hline \multicolumn{7}{|l|}{ BMI } \\
\hline Underweight $^{\mathrm{a}}$ vs. non-underweight ${ }^{\mathrm{b}}$ & 2.82 & $1.15-6.91$ & 0.023 & 2.65 & $1.08-6.50$ & 0.033 \\
\hline
\end{tabular}

${ }^{\mathrm{a} B M I}<18.5 \mathrm{~kg} / \mathrm{m}^{2}$. ${ }^{\mathrm{b}} \mathrm{BMI} \geq 18.5 \mathrm{~kg} / \mathrm{m}^{2}$. HR, hazard ratio; CI, confidence interval; ASA, American society of anesthesiologists; BMI, body mass index. 
Table III. Cox regression analyses of 3-year cancer-specific survival.

\begin{tabular}{|c|c|c|c|c|c|c|}
\hline \multirow[b]{2}{*}{ Variables } & \multicolumn{3}{|c|}{ Univariate analysis } & \multicolumn{3}{|c|}{ Multivariate analysis } \\
\hline & HR & $95 \% \mathrm{CI}$ & P-value & HR & $95 \% \mathrm{CI}$ & P-value \\
\hline \multicolumn{7}{|l|}{ Age, years } \\
\hline$\geq 85$ vs. $<85$ & 1.11 & $0.30-3.98$ & 0.87 & & & \\
\hline \multicolumn{7}{|l|}{ Gender } \\
\hline Male vs. female & 1.73 & $0.60-4.99$ & 0.30 & & & \\
\hline \multicolumn{7}{|l|}{ Charlson comorbidity index } \\
\hline$\geq 2$ vs. 0,1 & 0.91 & $0.20-4.07$ & 0.90 & & & \\
\hline \multicolumn{7}{|l|}{ ASA physical status } \\
\hline III, IV vs. I, II & 1.58 & $0.55-4.57$ & 0.39 & & & \\
\hline \multicolumn{7}{|l|}{ Tumor site } \\
\hline Rectum vs. colon & 1.04 & $0.32-3.33$ & 0.93 & & & \\
\hline \multicolumn{7}{|l|}{ Stage } \\
\hline III vs. I, II & 7.32 & $2.29-23.40$ & $<0.001$ & 6.69 & $2.08-21.44$ & 0.001 \\
\hline \multicolumn{7}{|l|}{ Histology } \\
\hline Undifferentiated vs. differentiated & 4.75 & $1.32-17.07$ & 0.016 & 4.37 & $1.15-16.62$ & 0.030 \\
\hline \multicolumn{7}{|l|}{ BMI } \\
\hline Underweight $^{\mathrm{a}}$ vs. non-underweight ${ }^{\mathrm{b}}$ & 3.13 & $1.08-9.02$ & 0.034 & 3.51 & $1.16-10.60$ & 0.025 \\
\hline
\end{tabular}

${ }^{\mathrm{a}} \mathrm{BMI}<18.5 \mathrm{~kg} / \mathrm{m}^{2} .{ }^{\mathrm{b}} \mathrm{BMI} \geq 18.5 \mathrm{~kg} / \mathrm{m}^{2}$. HR, hazard ratio; CI, confidence interval; ASA, American society of anesthesiologists; BMI, body mass index.
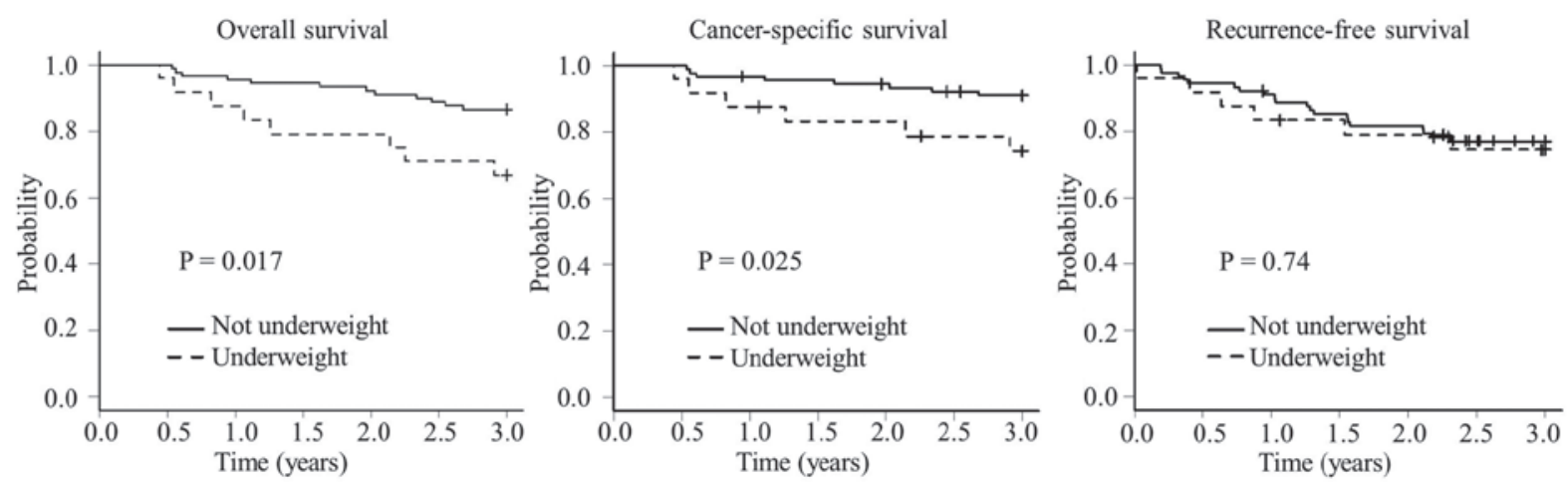

Figure 1. Survival curves of elderly patients who underwent curative surgery for colorectal cancer. Kaplan-Meier estimates of the overall, cancer-specific and recurrence-free survival of patients in the underweight $\left(\mathrm{BMI}<18.5 \mathrm{~kg} / \mathrm{m}^{2} ; \mathrm{n}=24\right)$ and non-underweight $\left(\mathrm{BMI} \geq 18.5 \mathrm{~kg} / \mathrm{m}^{2} ; \mathrm{n}=89\right)$ groups. BMI, body mass index.

of adverse outcomes, such as disability, poor quality of life and death' by the Special Interest Group of the European Sarcopenia Working Group in 2010 (18), and it is recognized as a multifactorial geriatric syndrome. The term 'sarcopenia' is used specifically to denote the loss of muscle mass and strength associated with aging, distinct from muscle loss due to other causes, such as immobility or neurological damage. Sarcopenia is independently associated with an increased risk of functional impairment, falls, disability and mortality in the elderly (19). The prevalence of sarcopenia is $50 \%$ in individuals aged $\geq 80$ years (18), and several reports demonstrated that sarcopenia is a negative prognostic factor in malignancies, including melanoma (20), hepatocellular carcinoma (21) and diffuse large B-cell lymphoma (22).
Cachexia may be a cause of loss of body fat mass (23). It has been reported that the loss of body fat content late in life is associated with premature death, micronutrient deficiencies, frailty, increased hospital admission, an increased risk of disability from falls and delayed recovery from injury (24-27). In addition, loss of body fat content has been reported to be associated with shorter survival in advanced cancer patients, although the underlying mechanism of this association has not yet been fully elucidated $(28,29)$. One possible explanation is that fat represents the main energy store of the body, and it may be one of the components predicting malnutrition-related risks of mortality and morbidity; thus, body fat confers survival advantages in elderly patients (30). 
Although BMI is a simple and useful tool in clinical practice for assessing adult nutritional status, two recent studies revealed that it cannot be used to assess individual components of body weight, such as regional fat distribution or muscle volume; thus, muscular individuals may be incorrectly categorized as overweight or obese $(31,32)$. The authors of those studies also suggested that other parameters denoting body composition, such as fat mass or muscle mass assessed by bioelectrical impedance analyses, dual-energy X-ray absorptiometry and magnetic resonance imaging or computed tomography imaging, would be more useful predictors of survival compared with BMI $(31,32)$. Further studies are required to evaluate the association between BMI and other parameters, and to identify better predictors of appropriate body composition.

The limitations of the present study include its retrospective design, small sample size and lack of data such as physical activity, diet, smoking status and changes in body weight prior to surgery. In regard to the sample size, only $1(0.8 \%)$ of the 113 patients had a BMI of $\geq 30 \mathrm{~kg} / \mathrm{m}^{2}$. However, this reflects the distribution of BMI categories in Japan, where only a relatively small proportion of the middle-old and oldest-old populations have a BMI of $\geq 30 \mathrm{~kg} / \mathrm{m}^{2}$ (33).

In conclusion, the results of the present study indicate that underweight status is an independent poor prognostic factor in elderly CRC patients, which may exert an effect on treatment and post-treatment surveillance. Further studies are required to validate our findings and elucidate the mechanism underlying the negative effect of underweight status on the survival of these patients. The development of effective nutritional interventions may contribute to a better prognosis in such patients.

\section{Acknowledgements}

The authors would like to thank Ms. Yukako Oikawa for her clerical assistance.

\section{References}

1. Torre LA, Bray F, Siegel RL, Ferlay J, Lortet-Tieulent J and Jemal A: Global cancer statistics, 2012. CA Cancer J Clin 65: 87-108, 2015

2. Millan M, Merino S, Caro A, Feliu F, Escuder J and Francesch T: Treatment of colorectal cancer in the elderly. World J Gastrointest Oncol 7: 204-220, 2015.

3. Nelson H, Petrelli N, Carlin A, Couture J, Fleshman J, Guillem J, Miedema B, Ota D and Sargent D; National Cancer Institute Expert Panel: Guidelines 2000 for colon and rectal cancer surgery. J Natl Cancer Inst 93: 583-596, 2001.

4. Fiorelli A, Vicidomini G, Mazzella A, Messina G, Milione R, Di Crescenzo VG and Santini M: The influence of body mass index and weight loss on outcome of elderly patients undergoing lung cancer resection. Thorac Cardiovasc Surg 62: 578-587, 2014.

5. Alphs HH, Zahurak ML, Bristow RE and Díaz-Montes TP: Predictors of surgical outcome and survival among elderly women diagnosed with ovarian and primary peritoneal cancer. Gynecol Oncol 103: 1048-1053, 2006.

6. Bailey KV and Ferro-Luzzi A: Use of body mass index of adults in assessing individual and community nutritional status. Bull World Health Organ 73: 673-680, 1995.

7. Meyerhardt JA, Tepper JE, Niedzwiecki D, Hollis DR, McCollum AD, Brady D, O'Connell MJ, Mayer RJ, Cummings B, Willett $\mathrm{C}$, et al: Impact of body mass index on outcomes and treatment-related toxicity in patients with stage II and III rectal cancer: Findings from Intergroup Trial 0114. J Clin Oncol 22: 648-657, 2004.
8. Dignam JJ, Polite BN, Yothers G, Raich P, Colangelo L, O'Connell MJ and Wolmark N: Body mass index and outcomes in patients who receive adjuvant chemotherapy for colon cancer. J Natl Cancer Inst 98: 1647-1654, 2006.

9. Doria-Rose VP, Newcomb PA, Morimoto LM, Hampton JM and Trentham-Dietz A: Body mass index and the risk of death following the diagnosis of colorectal cancer in postmenopausal women (United States). Cancer Causes Control 17: 63-70, 2006.

10. Hines RB, Shanmugam C, Waterbor JW, McGwin G Jr, Funkhouser E, Coffey CS, Posey J and Manne U: Effect of comorbidity and body mass index on the survival of African-American and Caucasian patients with colon cancer. Cancer 115: 5798-5806, 2009.

11. Sinicrope FA, Foster NR, Sargent DJ, O'Connell MJ and Rankin C: Obesity is an independent prognostic variable in colon cancer survivors. Clin Cancer Res 16: 1884-1893, 2010.

12. Chin CC, Kuo YH, Yeh CY, Chen JS, Tang R, Changchien CR, Wang JY and Huang WS: Role of body mass index in colon cancer patients in Taiwan. World J Gastroenterol 18: 4191-4198, 2012.

13. Sinicrope FA, Foster NR, Yothers G, Benson A, Seitz JF, Labianca R, Goldberg RM, Degramont A, O'Connell MJ and Sargent DJ; Adjuvant Colon Cancer Endpoints (ACCENT) Group: Body mass index at diagnosis and survival among colon cancer patients enrolled in clinical trials of adjuvant chemotherapy. Cancer 119: 1528-1536, 2013.

14. Charlson ME, Pompei P, Ales KL and MacKenzie CR: A new method of classifying prognostic comorbidity in longitudinal studies: Development and validation. J Chronic Dis 40: 373-383, 1987.

15. Sobin LH, Gospodarowicz MK and Wittekind C eds: International union against cancer (UICC) TNM classification of malignant tumors. 7th edition. Wiley-Blackwell, Oxford, 2009.

16. Kanda Y: Investigation of the freely available easy-to-use software 'EZR' for medical statistics. Bone Marrow Transplant 48: 452-458, 2013.

17. Patel GS, Ullah S, Beeke C, Hakendorf P, Padbury R, Price TJ and Karapetis CS: Association of BMI with overall survival in patients with mCRC who received chemotherapy versus EGFR and VEGF-targeted therapies. Cancer Med 4: 1461-1471, 2015.

18. Fielding RA, Vellas B, Evans WJ, Bhasin S, Morley JE, Newman AB, Abellan van Kan G, Andrieu S, Bauer J, Breuille D, et al: Sarcopenia: An undiagnosed condition in older adults. Current consensus definition: Prevalence, etiology and consequences. International working group on sarcopenia. J Am Med Dir Assoc 12: 249-256, 2011.

19. Janssen I, Heymsfield SB and Ross R: Low relative skeletal muscle mass (sarcopenia) in older persons is associated with functional impairment and physical disability. J Am Geriatr Soc 50: 889-896, 2002.

20. Sabel MS, Lee J, Cai S, Englesbe MJ, Holcombe S and Wang S: Sarcopenia as a prognostic factor among patients with stage III melanoma. Ann Surg Oncol 18: 3579-3585, 2011.

21. Meza-Junco J, Montano-Loza AJ, Baracos VE, Prado CM, Bain VG, Beaumont C, Esfandiari N, Lieffers JR and Sawyer MB: Sarcopenia as a prognostic index of nutritional status in concurrent cirrhosis and hepatocellular carcinoma. J Clin Gastroenterol 47: 861-870, 2013

22. Lanic H, Kraut-Tauzia J, Modzelewski R, Clatot F, Mareschal S, Picquenot JM, Stamatoullas A, Leprêtre S, Tilly H and Jardin F: Sarcopenia is an independent prognostic factor in elderly patients with diffuse large B-cell lymphoma treated with immunochemotherapy. Leuk Lymphoma 55: 817-823, 2014.

23. Ali S and Garcia JM: Sarcopenia, cachexia and aging: Diagnosis, mechanisms and therapeutic options-a mini-review. Gerontology 60: 294-305, 2014.

24. Delmi M, Rapin CH, Bengoa JM, Delmas PD, Vasey H and Bonjour JP: Dietary supplementation in elderly patients with fractured neck of the femur. Lancet 335: 1013-1016, 1990.

25. Tayback M, Kumanyika S and Chee E: Body weight as a risk factor in the elderly. Arch Intern Med 150: 1065-1072, 1990.

26. Pamuk ER, Williamson DF, Madans J, Serdula MK, Kleinman JC and Byers T: Weight loss and mortality in a national cohort of adults, 1971-1987. Am J Epidemiol 136: 686-697, 1992.

27. Mowé M, Bøhmer T and Kindt E: Reduced nutritional status in an elderly population ( $>70 \mathrm{y}$ is probable before disease and possibly contributes to the development of disease. Am J Clin Nutr 59: 317-324, 1994 
28. Murphy RA, Wilke MS, Perrine M, Pawlowicz M, Mourtzakis M, Lieffers JR, Maneshgar M, Bruera E, Clandinin MT, Baracos VE and Mazurak VC: Loss of adipose tissue and plasma phospholipids: Relationship to survival in advanced cancer patients. Clin Nutr 29: 482-487, 2010

29. Fouladiun M, Körner U, Bosaeus I, Daneryd P, Hyltander A and Lundholm KG: Body composition and time course changes in regional distribution of fat and lean tissue in unselected cancer patients on palliative care-correlations with food intake, metabolism, exercise capacity, and hormones. Cancer 103: 2189-2198, 2005.

30. Bouillanne O, Dupont-Belmont C, Hay P, Hamon-Vilcot B, Cynober L and Aussel C: Fat mass protects hospitalized elderly persons against morbidity and mortality. Am J Clin Nutr 90: 505-510, 2009
31. Gonzalez MC, Pastore CA, Orlandi SP and Heymsfield SB: Obesity paradox in cancer: New insights provided by body composition. Am J Clin Nutr 99: 999-1005, 2014.

32. Fujiwara N, Nakagawa H, Kudo Y, Tateishi R, Taguri M, Watadani T, Nakagomi R, Kondo M, Nakatsuka T, Minami T, et al: Sarcopenia, intramuscular fat deposition, and visceral adiposity independently predict the outcomes of hepatocellular carcinoma. J Hepatol 63: 131-140, 2015.

33. National Surveys on Cardiovascular Diseases in 2000. http://www. mhlw.go.jp/toukei/list/junkanki_chousa.html. Accessed June 31, 2015 (In Japanese). 